\title{
Can diets containing insects promote animal health?
}

\author{
L. Gasco ${ }^{1}$, M. Finke ${ }^{2}$ and A. van Huis ${ }^{3 *}$ \\ ${ }^{1}$ Department of Agricultural, Forest, and Food Sciences (DISAFA), University of Turin, Largo Paolo Braccini 2,10095 \\ Grugliasco, Italy; ${ }^{2}$ Mark Finke LLC, 17028 E Wildcat Dr, Rio Verde, AZ 85263, USA; ${ }^{3}$ Laboratory of Entomology, Wageningen \\ University E Research, P.O. Box 16, 6700 AA Wageningen, the Netherlands; editor-in-chief@insectsasfoodandfeed.com
}

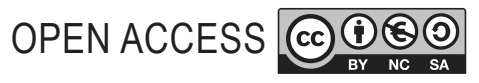

EDITORIAL

Insects are promising feedstuffs for animal feeds as they contain not only valuable nutrients but also particular compounds that seem to be able to modulate animal microbiota and to optimise animal health. So far, there has been little work on the effects of those insect derived compounds in animal feeding trails but initial investigations show promising results. This editorial discuss the effect of chitin, lauric acid, and anti-microbial peptides provided by insects.

\section{Introduction}

Population growth and increased welfare will be responsible for an increase in meat production especially in developing countries. The FAO's 'World Agriculture towards 2030/2050' report (FAO, 2017) forecasts an increase of $2.7 \%$ per year. The global feed market in 2017 reached a total of 1.07 billion metric tons with a feed industry growth of $13 \%$ over the past 5 years (Alltech, 2018). The (environmental) costs of conventional feed resources such as soybean meal (Prudêncio da Silva et al., 2010) and fishmeal (Olsen and Hasan, 2012) are high and their availability in the future will be limited. Insect-based feed products could be a part of the solution (Makkar et al., 2014). Several insect species can be efficiently raised on organic side streams and fed to a variety of animal species (Van Huis and Tomberlin, 2017). In general, most edible insect species appear to be good sources of amino acids, fatty acids, most minerals, and most B vitamins (Finke, 2002). The question that we address here is whether insects can have additional health benefits compared to conventional feed sources.

There are other considerations dealing with human health when insects are used as animal feed. Antibiotic resistance in humans is responsible for an estimated 23,000 and 25,000 deaths each year in the USA and Europe, respectively (Gelband et al., 2015). This is mainly caused by the use of antibiotics in livestock: estimated in 2010 to be about 63,000 tons and projected to grow $67 \%$ by 2030 (Van Boeckel et al., 2015). Approximately two thirds of antimicrobials are employed in livestock production as feed additives for chemotherapeutic and prophylactic purposes. They are also used to promote growth and improve feed efficiency, but this practice has been banned since 2006 (EC, 2003) in the European Union. Their overuse contributes to the spread of drug-resistant pathogens in both livestock and humans, posing a significant public health threat. For this reason, there is an urgent need to develop novel antimicrobial agents (Wang et al., 2016). The complex microbial communities living in an animal's gastrointestinal tract can be altered via the dietary inclusion of prebiotic compounds having a subsequent effect on the animal's immune system (Montalban-Arques et al., 2015).

\section{Chitin}

Chitin is a component of the exoskeleton of crustaceans and insects (Finke, 2007; Wasko et al., 2016). Chitin and chitin derivatives can stimulate innate immune cells (Lee et al., 2008). Neither fish, birds or mammals synthetize chitin, so it is a potential target for recognition by the immune system (Elieh Ali Komi et al., in press). For example addition of 1.0\% chitin or chitosan extracted from shrimp shells to the diet stimulates immune response and affords disease resistance in the kelp grouper, Epinephelus bruneus against infections of the protozoan parasite, Philasterides dicentrarchi (Harikrishnan et al., 2012). Similarly, feeding shrimp chitin to broilers inhibited the growth of the foodborne pathogens Escherichia coli and Salmonella in the intestine (Khempaka et al., 2011). Providing fermented yellow mealworm (Tenebrio molitor) and super mealworm (Zophobas morio) larval meal (obtained by fermenting the insect meals with Lactobacillus plantarum and Saccharomices cerevisiae) to broiler chicks, reduced cecal E. coli and Salmonella spp. and increased IgG and IgA levels (Islam and Yang, 2017). The reduction of pathogenic organisms was explained as 
a combined effect of chitin and probiotics and the authors stated that larval probiotics could be used as an alternative to antibiotics.

Maintaining the optimal intestinal microbial communities of fish is important for the practice of aquaculture as it can affect the vulnerability of the host fish to diseases (Ghanbari et al., 2015). In fish, research showed chitin is able to reduce pathogen growth by enhancing the growth of beneficial intestinal microbiota with positive effects on performance and health (Karlsen et al., 2017). Feeding black soldier fly (Hermetia illucens) larval meal to rainbow trout (Oncorhynchus mykiss), showed an increased incidence of bacteria of the Carnobacterium genus, which are wellknown probiotics in salmonids and have several functions: in vitro growth inhibition of pathogens, stimulation of non-specific immune response and in vivo improvement of disease resistance (Bruni et al., 2018).

European sea bass fingerlings fed T. molitor larval meal had enhanced lysozyme antibacterial activity and serum trypsin inhibition (Henry et al., 2018). Following the ingestion of maggot meal of the housefly (Musca domestica), black carp (Mylopharyngodon piceus) showed improvement in both lysozyme and complement activity and reduced mortality due to Aeromonas hydrophila (Ming et al., 2013). Similarly, Ido et al. (2015) showed how low dietary levels of housefly larval meal led to innate immune system activation in red sea bream and protected against Edwardsiella tarda infection. The authors assigned this effect to bioactive compounds such as chitin or antimicrobial substances present in the housefly meal.

Chitin has hypolipidaemic and hypocholesterolaemic properties (Koide, 1998) in broiler chickens, resulting in a reduction in body fat and possibly the production of leaner meat (Hossain and Blair, 2007). Broilers fed diets with yellow mealworm larval meal had the lowest albumin to globulin ratio suggesting an enhanced immune response and a better disease resistance, likely due to the prebiotic effects of chitin (Bovera et al., 2015). Similar results were found for laying hens fed about 1.02 g per day of chitin provided by dietary black soldier fly larval meal inclusion (Marono et al., 2017). The same authors also reported lower serum cholesterol and triglyceride levels in birds fed diets containing black soldier fly compared to those fed a soybean meal based diet. They ascribed these results to the ability of chitin to bind to bile acids and free fatty acids.

\section{Lauric acid}

Lauric acid is known to have profound antiviral and antibacterial activity (Lieberman et al., 2006). Black soldier flies are rich in fat, with levels ranging between 15 and 49\% on dry matter basis (Makkar et al., 2014). Notably, the fatty acid profile of the prepupae is high in the medium-chain fatty acid lauric acid (C12:0). The fat of prepupae reared on organic waste streams with high amounts of starch contains up to $60 \%$ lauric acid (Spranghers et al., 2017). Medium chain fatty acids are well known for their antimicrobial effects on gut microbiota, while lauric acid is particularly active against gram positive bacteria (Dierick et al., 2002; Skřivanová et al., 2005). Recently, an in vitro trial showed that black soldier fly prepupal fat $(0.58 \mathrm{~g} \mathrm{C12:0/100} \mathrm{ml})$ suppressed growth of lactobacilli, with the most substantial antibacterial effects against D-streptococci infections in pigs (Spranghers et al., 2018). In in vivo conditions it has been suggested that these positive effects are most likely seen when farming conditions and/or health status are sub-optimal (Schiavone et al., in press). The possible antimicrobial effects of fat (C12:0) of the black soldier fly could provide an important added value when complete larvae/prepupae are used as a protein source in the feed of monogastrics (Spranghers et al., 2017).

\section{Antimicrobial peptides}

Over use of antibiotics has been responsible for restricting the use of antibiotics in the feed industry, agriculture and veterinary medicine. Most antibiotics are small, cationic proteins that exhibit activity against bacteria and/or fungi, as well as certain parasites and viruses (Yi et al., 2014). The greatest diversity of anti-microbial peptides are found in insects (Tonk and Vilcinskas, 2017). Until now, more than 150 insect proteins with antimicrobial activity have been identified and can be classified as follows: (1) $\alpha$-helical peptides (e.g. cecropin and moricin); (2) cysteinerich peptides (e.g. insect defensin and drosomycin); (3) prolinerich peptides (e.g. apidaecin, drosocin, and lebocin); and (4) glycine-rich proteins (e.g. attacin and gloverin) (Otvos, 2000). Insects living in germ-infested environments (e.g. flies) are a potent source of antimicrobials (Lee $e t$ al., 2012). Anti-microbial peptides have an effect on different bacteria and the risk of bacterial resistance is low (Chernysh et al., 2015). In pigs and broilers anti-microbial peptides improve growth performance, promotes nutrient digestibility and gut health, positively alters intestinal microbiota, and enhances immune function (Wang et al., 2016). Ji et al. (2016) reported a marked decrease in diarrhoea of weaning pigs from day 15 to day 28 of the trial due to the dietary supplementation with yellow mealworm, giant mealworm and housefly meal, and ascribed this result to the antimicrobial peptide effect of insect meals.

In broilers the anti-microbial peptide P5 can be used as an alternative to antibiotics as a growth promoter (Choi et al., 2013a,b). Antimicrobial peptides provide great hope due to the global problem related to the increasing resistance of bacteria to antibiotics. Bactericidal insect antimicrobial peptides may also protect against viruses and fungi. Although they have not yet been introduced on the market, according to Józefiak and Engberg (2017) 
the outlook is promising, but much work remains to be done to arrive at large scale production for the application in livestock.

\section{Conclusions}

Insect meals are considered one of the most promising sources of alternative proteins for the sustainable future of animal feeds. Recent findings showed how insects could also be sources of valuable compounds able to exert positive effects on the animal immune system promoting health and reducing the use of antibiotics in animal production. Nevertheless, many aspects still need to be clarified and further research is highly recommended.

\section{References}

Alltech, 2018. $7^{\text {th }}$ annual Alltech global feed survey. Alltech, Nicholasville, KY, USA. Available at: https://go.alltech.com/alltechfeed-survey.

Bovera, F., Piccolo, G., Gasco, L., Marono, S., Loponte, R., Vassalotti, G., Mastellone, V., Lombardi, P., Attia, Y.A. and Nizza, A., 2015. Yellow mealworm larvae (Tenebrio molitor, L.) as possible alternative to soybean meal in broiler diets. British Poultry Science 56: 569-575.

Bruni, L., Pastorelli, R., Viti, C., Gasco, L. and Parisi, G., 2018. Characterisation of the intestinal microbial communities of rainbow trout (Oncorhynchus mykiss) fed with Hermetia illucens (black soldier fly) partially defatted larva meal as partial dietary protein source. Aquaculture 487: 56-63.

Chernysh, S., Gordya, N. and Suborova, T., 2015. Insect antimicrobial peptide complexes prevent resistance development in bacteria. PLOS ONE 10: e0130788.

Choi, S.C., Ingale, S.L., Kim, J.S., Park, Y.K., Kwon, I.K. and Chae, B.J., 2013a. An antimicrobial peptide-A3: effects on growth performance, nutrient retention, intestinal and faecal microflora and intestinal morphology of broilers. British Poultry Science 54: 738-746.

Choi, S.C., Ingale, S.L., Kim, J.S., Park, Y.K., Kwon, I.K. and Chae, B.J., 2013b. Effects of dietary supplementation with an antimicrobial peptide-P5 on growth performance, nutrient retention, excreta and intestinal microflora and intestinal morphology of broilers. Animal Feed Science and Technology 185: 78-84.

Dierick, N.A., Decuypere, J.A., Molly, K., Van Beek, E. and Vanderbeke, E., 2002. The combined use of triacylglycerols containing mediumchain fatty acids (MCFAs) and exogenous lipolytic enzymes as an alternative for nutritional antibiotics in piglet nutrition: I. In vitro screening of the release of MCFAs from selected fat sources by selected exogenous lipolytic enzymes under simulated pig gastric conditions and their effects on the gut flora of piglets. Livestock Production Science 75: 129-142.

Elieh Ali Komi, D., Sharma, L. and Dela Cruz, C.S., in press. Chitin and its effects on inflammatory and immune responses. Clinical Reviews in Allergy and Immunology, https://doi.org/10.1007/ s12016-017-8600-0.
European Commission (EC), 2003. Regulation (EC) No 1831/2003 of the European Parliament and of the Council of 22 September 2003 on additives for use in animal nutrition. Official Journal of the European Union L268: 29-43.

Food and Agriculture Organisation (FAO), 2017. The state of food and agriculture. leveraging food systems for inclusive rural transition. FAO, Rome, Italy. Available at: http://www.fao.org/3/a-I7658e.pdf.

Finke M., 2002. Complete nutrient composition of commercially raised invertebrates used as food for insectivores. Zoo Biology 21: 286-293.

Finke M., 2007. An estimate of chitin in raw whole insects. Zoo Biology 26: 105-115.

Gelband, H., Miller, P., Molly, Pant, S., Gandra, S., Levinson, J., Barter, D., White, A. and Laxminarayan, R., 2015. The state of the world's antibiotics 2015. Wound Healing Southern Africa 8: 30-34.

Ghanbari, M., Kneifel, W. and Domig, K.J., 2015. A new view of the fish gut microbiome: advances from next-generation sequencing. Aquaculture 448: 464-475.

Harikrishnan, R., Kim, J.-S., Balasundaram, C. and Heo, M.-S., 2012. Dietary supplementation with chitin and chitosan on haematology and innate immune response in Epinephelus bruneus against Philasterides dicentrarchi. Experimental Parasitology 131: 116-124.

Henry, M.A., Gasco, L., Chatzifotis, S. and Piccolo, G., 2018. Does dietary insect meal affect the fish immune system? The case of mealworm, Tenebrio molitor on European sea bass, Dicentrarchus labrax. Developmental and Comparative Immunology 81: 204-209.

Hossain, S.M. and Blair, R., 2007. Chitin utilisation by broilers and its effect on body composition and blood metabolites. British Poultry Science 48: 33-38.

Ido, A., Iwai, T., Ito, K., Ohta, T., Mizushige, T., Kishida, T., Miura, C. and Miura, T., 2015. Dietary effects of housefly (Musca domestica) (Diptera: Muscidae) pupae on the growth performance and the resistance against bacterial pathogen in red sea bream (Pagrus major) (Perciformes: Sparidae). Applied Entomology and Zoology 50: 213-221.

Islam, M.M. and Yang, C.-J., 2017. Efficacy of mealworm and super mealworm larvae probiotics as an alternative to antibiotics challenged orally with Salmonella and E. coli infection in broiler chicks. Poultry Science 96: 27-34.

Ji, Y.J., Liu, H.N., Kong, X.F., Blachier, F., Geng, M.M., Liu, Y.Y. and. Yin, Y.L., 2016. Use of insect powder as a source of dietary protein in early-weaned piglets. Journal of Animal Science 94: 111-116.

Józefiak, A. and Engberg, R.M., 2017. Insect proteins as a potential source of antimicrobial peptides in livestock production. A review. Journal of Animal and Feed Sciences 26: 87-99.

Karlsen, Ø., Amlund, H., Berg, A. and Olsen, R.E., 2017. The effect of dietary chitin on growth and nutrient digestibility in farmed Atlantic cod, Atlantic salmon and Atlantic halibut. Aquaculture Research 48: 123-133.

Khempaka, S., Chitsatchapong, C. and Molee, W., 2011. Effect of chitin and protein constituents in shrimp head meal on growth performance, nutrient digestibility, intestinal microbial populations, volatile fatty acids, and ammonia production in broilers. Journal of Applied Poultry Research 20: 1-11.

Koide, S.S., 1998. Chitin-chitosan: properties, benefits and risks. Nutrition Research 18: 1091-1101. 
Lee, C.G., Silva, C.A.D., Lee, J.-Y., Hartl, D. and Elias, J.A., 2008. Chitin regulation of immune responses: an old molecule with new roles. Current Opinion in Immunology 20: 684-689.

Lee, S., Siddiqui, R. and Khan, N.A., 2012. Animals living in polluted environments are potential source of antimicrobials against infectious agents. Pathogens and Global Health 106: 218-223.

Lieberman, S., Enig, M. and Preuss, H., 2006. A review of monolaurin an lauric acid: natural virucidal 348 and bactericidal agents. Alternative \& Complementary Therapies 12: 310-314.

Makkar, H.P.S., Tran, G., Heuzé, V. and Ankers, P., 2014. State-ofthe-art on use of insects as animal feed. Animal Feed Science and Technology 197: 1-33.

Marono, S., Loponte, R., Lombardi, P., Vassalotti, G., Pero, M.E., Russo, F., Gasco, L., Parisi, G., Piccolo, G., Nizza, S., Di Meo, C., Attia, Y.A. and Bovera, F., 2017. Productive performance and blood profiles of laying hens fed Hermetia illucens larvae meal as total replacement of soybean meal from 24 to 45 weeks of age. Poultry Science 96: 1783-1790.

Ming, J., Ye, J., Zhang, Y., Yang, X., Wu, C., Shao, X. and Liu, P., 2013. The influence of maggot meal and l-carnitine on growth, immunity, antioxidant indices and disease resistance of black carp (Mylopharyngodon piceus). Journal of the Chinese Cereals and Oils Association 28: 80-86.

Montalban-Arques, A., De Schryver, P., Bossier, P., Gorkiewicz, G., Mulero, V., Gatlin, D.M. III and Galindo-Villegas, J., 2015. Selective manipulation of the gut microbiota improves immune status in vertebrates. Frontiers in Immunology 6: 512.

Olsen, R.L. and Hasan, M.R., 2012. A limited supply of fishmeal: impact on future increases in global aquaculture production. Trends in Food Science and Technology 27: 120-128.

Otvos Jr., L., 2000. Antibacterial peptides isolated from insects. Journal of Peptide Science 6: 497-511.

Prudêncio da Silva, V., Van der Werf, H.M.G., Spies, A. and Soares, S.R., 2010. Variability in environmental impacts of Brazilian soybean according to crop production and transport scenarios. Journal of Environmental Management 91: 1831-1839.
Schiavone, A., Dabbou, S., De Marco, M., Cullere, M., Biasato, I., Biasibetti, E., Capucchio, M.T., Bergagna, S., Dezzutto, D., Meneguz, M., Gai, F., Dalle Zotte, A. and Gasco, L., in press. Black soldier fly larva fat inclusion in finisher broiler chicken diet as an alternative fat source. Animal, https://doi.org/10.1017/S1751731117003743.

Skřivanová, E., Marounek, M., Dlouhá, G. and Kaňka, J., 2005. Susceptibility of Clostridium perfringens to C2-C18 fatty acids. Letters in Applied Microbiology 41: 77-81.

Spranghers, T., Ottoboni, M., Klootwijk, C., Ovyn, A., Deboosere, S., De Meulenaer, B., Michiels, J., Eeckhout, M., De Clercq, P. and De Smet, S., 2017. Nutritional composition of black soldier fly (Hermetia illucens) prepupae reared on different organic waste substrates. Journal of the Science of Food and Agriculture 97: 2594-2600.

Spranghers, T., Michiels, J., Vrancx, J., Ovyn, A., Eeckhout, M., De Clercq, P. and De Smet, S., 2018. Gut antimicrobial effects and nutritional value of black soldier fly (Hermetia illucens L.) prepupae for weaned piglets. Animal Feed Science and Technology 235: 33-42.

Tonk, M. and Vilcinskas, A., 2017. The medical potential of antimicrobial peptides from insects. Current Topics in Medicinal Chemistry 17: 554-575.

Van Boeckel, T.P., Brower, C., Gilbert, M., Grenfell, B.T., Levin, S.A., Robinson, T.P., Teillant, A. and Laxminarayan, R., 2015. Global trends in antimicrobial use in food animals. Proceedings of the National Academy of Sciences of the USA 112: 5649-5654.

Van Huis, A. and Tomberlin, J., 2017. The potential of insects as food and feed. In: Van Huis, A. and Tomberlin, J.K. (eds.) Insects as food and feed: from production to consumption. Wageningen Academic Publishers, Wageningen, the Netherlands, pp. 25-58.

Wang, S., Zeng, X., Yang, Q. and Qiao, S., 2016. Antimicrobial peptides as potential alternatives to antibiotics in food animal industry. International Journal of Molecular Sciences 17: 603.

Wasko, A., Bulak, P., Polak-Berecka, M., Nowak, K., Polakowski, C. and Bieganowski, A., 2016. The first report of the physicochemical structure of chitin isolated from Hermetia illucens. International Journal of Biological Macromolecules 92: 316-320.

Yi, H.-Y., Chowdhury, M., Huang, Y.-D. and Yu, X.-Q., 2014. Insect antimicrobial peptides and their applications. Applied Microbiology and Biotechnology 98: 5807-5822. 